\title{
The Circle Is Closing - OBESITY Facts Launched as Official Journal of IFSO-EC
}

\author{
Martin Fried \\ Clinical Center for Minimally Invasive and Bariatric Surgery, 1st Medical Faculty, Charles University, Prague, Czech Republic
}

The International Federation for the Surgery of Obesity and Metabolic Diseases - European Chapter (IFSO-EC) is joining the Editorial Board of OBEsity FACTS. OBEsity FACTS becomes affiliated journal of IFSO-EC.

Seemingly a short statement that can be easily overlooked, these two sentences however close the circle of almost half of a century of ongoing endeavor and scientific discussion on the role of surgery in obesity management. Today, we are at a threshold that have both symbolic and very practical meaning for the current therapy of the obesity epidemic.

Looking back to the history, bariatric surgery (surgical treatment of severe obesity as a disease) started more than 50 years ago. In middle of the last century a severely obese patient in whom all previous conservative attempts failed in the long term was operated on with the aim to substantially reduce his weight and thus to save his life. The patient was suffering not only from massive obesity but also from several serious obesity-related co-morbidities such as type 2 diabetes mellitus, hypertension, dyslipidemia, and spine problems. In order to reduce his morbid overweight and improve his above mentioned co-morbidities, the patient's small intestine was shortened. Amazingly, shortly after the operation the patient's condition substantially improved. His long lasting co-morbidities related to his massive obesity subsided and some of them even completely resolved.

During the following decades bariatric surgery has passed through several waves of appreciation and skepticism. Bariatric surgeons has made great efforts to improve surgical interventions and increase the acceptance of bariatric procedures. Scientifically sound bariatric data gradually changed minds of many of those who were skeptical in the beginning. Due to its high safety and its excellent results with respect to long lasting weight loss and amelioration of many of obesity related co-morbidities, bariatric surgery meanwhile is well established in obesity management.
Supported by the understanding that successful management of obesity is rather complex and that there is no ideal, 'one fits all' treatment modality, an unforeseen change in the perception of bariatric surgery has happened. In many European countries the main topic of discussions shifted from if bariatric surgery at all ...' to 'when to operate, who is the best candidate for surgery and how to ideally combine surgical and non-surgical treatment modalities ...' today multi- and interdisciplinary treatment approaches have prevailed in Europe. It became obvious that multi- and interdisciplinary collaboration in obesity management is not only helpful, but in fact the only way to achieve success.

An excellent example how important collaborative activities can be, is the preparation of guidelines for obesity treatment. Such guidelines on obesity management created through interdisciplinary work were recently published in several peer reviewed scientific journals including OBEsITY FACTS. Just to mention some of the most recent:

- The 'Interdisciplinary European Guidelines for Surgery of Severe Obesity' [1] were laid down by the 'Bariatric Scientific Collaborative Group' (BSCG). In the foreword of the guidelines it was stated that 'The BSCG was appointed in 2005 through a joint effort of the major European Scientific Societies which are active in the field of obesity management. Societies that constituted this panel were: International Federation for the Surgery of Obesity - European Chapter (IFSO-EC), European Association for the Study of Obesity (EASO), European Childhood Obesity Group (ECOG) and the International Obesity Task Force (IOTF) which was represented during the completion process by its representatives'.

The BSCG comprised officers representing the respective Scientific Societies (including four acting Presidents, two past Presidents, one Honorary President, and three Executive Directors). Moreover, the panel was balanced by the

\begin{tabular}{ll}
\hline KARGER & @ 2008 S. Karger GmbH, Freiburg \\
Fax +49 7614520714 & Accessible online at: \\
$\begin{array}{l}\text { E-mail Information@Karger.de } \\
\text { www.karger.com }\end{array}$ & www.karger.com/ofa
\end{tabular}


presence of many other opinion leaders in the field of obesity. The composition of the BSCG allowed coverage of the key disciplines in comprehensive obesity management as well as being reflective of European geographic and ethnic diversity.

- 'Management of Obesity in Adults: European Clinical Practice Guidelines' [2] were created and published in a strictly multidisciplinary collaboration as well. The introductory paragraph of the guidelines states that 'these European guidelines on the management of obesity in adults were developed to address the need for evidence-based recommendations for the management of obesity at the individual level and to establish a basis for a more uniform approach in obesity management across Europe. Our aim is to provide physicians, health-care policy makers and health-care carriers with essential elements of good clinical practice in the management of obesity. The working group of the European Obesity Management Task Force of the European Association for the Study of Obesity (EASO), which performed this task, was composed of experts, representing key disciplines in comprehensive obesity management and reflecting European geographical and ethnic diversity. The group also included a representative of the International Federation for the Surgery of Obesity - European Chapter (IFSO-EC). We reviewed published national obesity guidelines ... from several European countries. At the same time, we have adopted a rigorous, evidence-based approach to the development of the practice recommendations ...'

The circle is closing. After more than 50 years of endeavor and battle for mutual understanding, respect and collaboration in the effort to help obese patients and treat their disease, a further very important step has been made.

Over the past 3 years both the EASO and IFSO-EC have discussed and looked for the possibility of launching a new, inter- disciplinary journal focused on obesity management. Eventually EASO and IFSO-EC agreed to share OBESITY FACTS as platform to exchange interdisciplinary views and ideas on obesity treatment. The European orientation which is mirrored by journal's subtitle 'The European Journal of Obesity' also reflects the fact that EASO as well as IFSO-EC represent mainly European membership.

IFSO-EC will be represented in the Editorial Board of OBESITY FACTS by key opinion leaders in the field of bariatric surgery of five European Countries, Austria, Czech Republic, France, Germany and Spain.

Bariatric papers which will be published in the journal doubtless will contribute to deepening the multidisciplinary understanding of the physiological effects of surgical treatment of obesity. Hopefully these papers will also contribute to further research and collaboration in a relatively new surgical field metabolic surgery. This specialty increasingly has gained in importance since it could be shown in the past few years that bariatric surgery has almost immediate positive effects on several metabolic diseases such as type 2 diabetes mellitus. Authors are encouraged to submit manuscripts dealing with this fascinating topic of obesity.

Enjoy reading OBESITY FACTS with the new bariatric part included!

\section{References}

1 Fried M, Hainer V, Basdevant A, Buchwald H, Deitel M, Finer N, Greve JWM, Horber F, Mathus-Vliegen E, Scopinaro N, Steffen R, Tsigos C, Weiner R, Widhalm K: Interdisciplinary European guidelines on surgery of severe obesity. Obesity Facts 2008:1:52-59.

2 Tsigos C, Hainer V, Basedvant A, Finer N, Fried M, Mathus-Vliegen E, Micic D, Maislos M, Roman, G, Schutz Y, Toplak H, Zahorska-Markiewicz B, for the Obesity Management Task Force of the European Association for the Study of Obesity: Management of obesity in adults: European clinical practice guidelines. Obesity Facts 2008;1:106-116. 